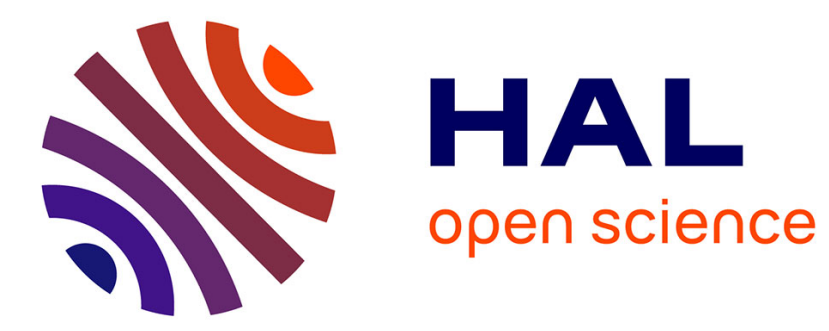

\title{
Through-bond homonuclear correlation experiments in Solid-state NMR applied to quadrupolar nuclei in Al-O-P-O-Al chains.
}

Michaël Deschamps, Franck Fayon, Valérie Montouillout, Dominique Massiot

\section{- To cite this version:}

Michaël Deschamps, Franck Fayon, Valérie Montouillout, Dominique Massiot. Through-bond homonuclear correlation experiments in Solid-state NMR applied to quadrupolar nuclei in Al-O-P-O-Al chains.. Chemical Communications, 2006, N/A, pp.1924-1925. 10.1039/b600514d . hal-00021321

\section{HAL Id: hal-00021321 \\ https://hal.science/hal-00021321}

Submitted on 21 Mar 2006

HAL is a multi-disciplinary open access archive for the deposit and dissemination of scientific research documents, whether they are published or not. The documents may come from teaching and research institutions in France or abroad, or from public or private research centers.
L'archive ouverte pluridisciplinaire HAL, est destinée au dépôt et à la diffusion de documents scientifiques de niveau recherche, publiés ou non, émanant des établissements d'enseignement et de recherche français ou étrangers, des laboratoires publics ou privés. 


\title{
Through-bond homonuclear correlation experiments in Solid-state NMR applied to quadrupolar nuclei in Al-O-P-O-Al chains.
}

\author{
Michaël Deschamps, ${ }^{* a}$ Franck Fayon, ${ }^{a}$ Valérie Montouillout ${ }^{a}$ and Dominique Massiot ${ }^{a}$
}

DOI: 10.1039/b600514d

Through-bond homonuclear correlation experiments can be realised in solids between spins of type $X$, separated by four chemical bonds, in $\mathrm{X}-\mathrm{O}-\mathrm{Y}-\mathrm{O}-\mathrm{X}$ motives, provided a $\mathrm{J}$ coupling ${ }_{10}$ between $\mathrm{X}$ and $\mathrm{Y}$ exists: central transitions of quadrupolar ${ }^{27} \mathrm{Al}$ spins can be correlated via the $\mathrm{J}^{2}$ scalar coupling between ${ }^{27} \mathrm{Al}$ $(\mathrm{X})$ and ${ }^{31} \mathrm{P}(\mathrm{Y})$ in materials featuring Al-O-P-O-Al motives.

Solid-state NMR is widely recognized as an extremely powerful tool for the structural characterization of a large variety of solid 15 materials (inorganic materials like zeolites or glasses and organic materials like proteins or hybrid organic-inorganic...). The power of this method relies on the ability to characterize the local environment (chemical shift), the spatial proximity (through-space dipolar interaction) or the chemical bonding (through-bond scalar 20 coupling). Quadrupolar nuclei (spin $>1 / 2$ ) are actually difficult to deal with, as they exhibit fast relaxation in liquid phase and strong first and second order broadenings in solid state. A 2D NMR HMQC experiment has been recently introduced to characterize through-bond heteronuclear correlations between adjacent ${ }_{25}$ quadrupolar nuclei (in ${ }^{27} \mathrm{Al}-{ }^{17} \mathrm{O}$ systems) under MAS in solids. ${ }^{1}$ Homonuclear through-space correlations methods have also been introduced, using dipolar interactions between neighbouring quadrupolar nuclei. $^{2-4}$

We present here the first homonuclear correlation experiment 30 applied to quadrupolar nuclei making use of the sole scalar Jcoupling. This experiment uses a relayed transfer from ${ }^{27} \mathrm{Al}$ to neighboring ${ }^{31} \mathrm{P}$ and to a second ${ }^{27} \mathrm{Al}$ and is based on an Heteronuclear Single Quantum Correlation (HSQC) experiment. ${ }^{5}$ This experiment, shown in Figure 1, and further referred to as an ${ }_{35}$ Homonuclear-Heteronuclear Single Quantum Correlation experiment (H-HSQC), provides experimental evidence for through-bond homonuclear correlations between quadrupolar nuclei separated by four chemical bonds.

Weak pulses have been used on the ${ }^{27} \mathrm{Al}$ central transition 40 (further described as a fictitious spin-1/2), which is prepared by enhancement from the satellite transitions by $\mathrm{DFS}^{6}$ or $\mathrm{RAPT}^{7}$ transfer. The first INEPT transfer allows for the creation of a density operator proportional to $2 \mathrm{Al}_{\mathrm{z}, \mathrm{CT}}^{1} \mathrm{P}_{\mathrm{y}}$ after an evolution under the scalar coupling during a delay $2 \tau$. The transfer efficiency from ${ }_{45}$ the central transition of ${ }^{27} \mathrm{Al}$ to ${ }^{31} \mathrm{P}$ is equal to $\sin (2 \pi \mathrm{J} \tau) \cos ^{\mathrm{n}-1}(2 \pi$ $\mathrm{J} \tau$ ), where $\mathrm{n}$ is the number of ${ }^{31} \mathrm{P}$ atoms $\mathrm{J}$-coupled to the central transition of the ${ }^{27} \mathrm{Al}$ spin. The optimum transfers for $\mathrm{n}=\{1,2,3,4\}$

${ }^{a}$ CRMHT-CNRS, 1D, Avenue de la Recherche Scientifique, 45071 Orléans cedex 2, FRANCE. Fax: [+33] (0)2 386381 03; Tel: [+33] (0)2 382555 11; E-mail: deschamps@cnrs-orleans.fr

$\uparrow$ Electronic Supplementary Information (ESI) available: [details of any supplementary information available should be included here]. See http://dx.doi.org/10.1039/b000000x/

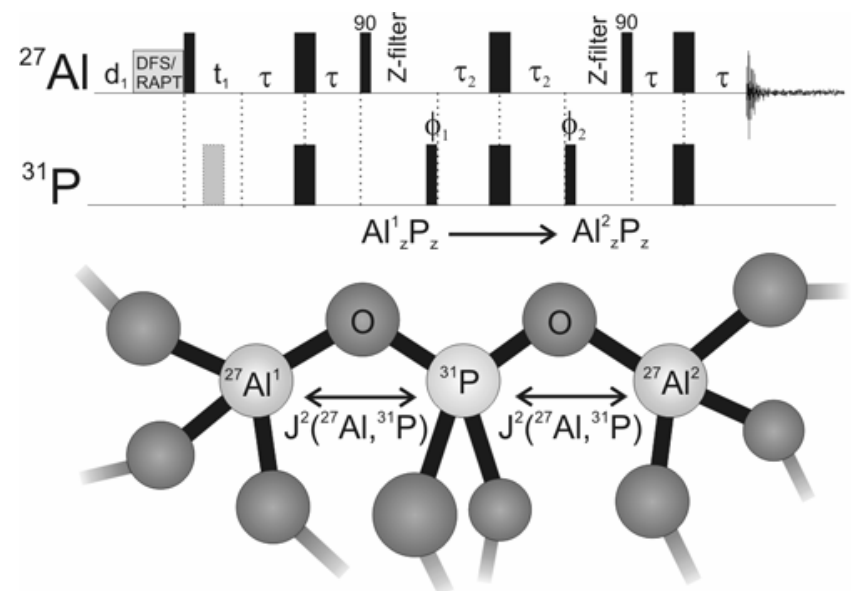

Fig.1 The H-HSQC experiment is presented, featuring the magnetization transfer from the $\mathrm{Al}^{1}$ spin to the $\mathrm{Al}^{2}$ spin. A scheme of the atoms and the scalar couplings involved is shown below in the ${ }^{27} \mathrm{Al} /{ }^{31} \mathrm{P}$ case. The DFS or RAPT (signal enhancement for the Central Transition of the quadrupolar nucleus) and ${ }^{31} \mathrm{P} 180^{\circ}$ pulses (to prevent the evolution under the scalar coupling of ${ }^{27} \mathrm{Al}$ magnetization during the $\mathrm{t}_{1}$ delay) in grey are optional. The Bruker pulse sequence is given in the supplementary material. The States method was used to achieve quadrature detection in the indirect dimension. Two Z-filters (300 rotor periods) have been used to suppress unwanted contributions; these can actually be suppressed for amorphous materials. $^{8}$

are obtained when $\tau \approx\left\{(4 \mathrm{~J})^{-1},(8 \mathrm{~J})^{-1},(10 \mathrm{~J})^{-1},(12 \mathrm{~J})^{-1}\right\}$ respectively, provided the dephasing of the magnetization can be neglected, and ${ }_{50}$ assuming equal $\mathrm{J}$ values. The second echo period $\left(2 \tau_{2}\right)$ allows for the conversion of $\mathrm{Al}_{\mathrm{z}, \mathrm{CT}}^{1} \mathrm{P}_{\mathrm{y}}$ into $\mathrm{Al}_{\mathrm{z}, \mathrm{CT}}^{2} \mathrm{P}_{\mathrm{y}}$. The diagonal signal corresponds to the remaining $\mathrm{Al}^{1}{ }_{\mathrm{z}, \mathrm{CT}} \mathrm{P}_{\mathrm{y}}$ term. This transfer depends upon n', the number of ${ }^{27} \mathrm{Al}$ spins coupled to the ${ }^{31} \mathrm{P}$ nucleus. The functions describing the intensities of the diagonal signal ${ }_{55}\left(\mathrm{Al}^{1}{ }_{\mathrm{z}, \mathrm{CT}} \mathrm{P}_{\mathrm{y}}\right)$ and of the cross-peaks (stemming from the conversion of $\mathrm{Al}^{1}{ }_{\mathrm{z}, \mathrm{CT}} \mathrm{P}_{\mathrm{y}}$ into $\mathrm{Al}_{\mathrm{z}, \mathrm{CT}} \mathrm{P}_{\mathrm{y}}$ ) are given below. Equations (1), (2) and (3) correspond to $n^{\prime}=2,3$ and 4 , respectively, with an initial density operator $\sigma\left(\tau_{2}=0\right)=2 \mathrm{Al}_{\mathrm{z}, \mathrm{CT}}^{1} \mathrm{P}_{\mathrm{y}}$.

$$
\begin{aligned}
& I\left(A l_{z}^{1} P_{y}\right)=-1 / 2\left[1+\cos 4 \pi J \tau_{2}\right] \text { and } I\left(A l_{z}^{2} P_{y}\right)=-1 / 2\left[-1+\cos 4 \pi J \tau_{2}\right] \\
& I\left(A l_{z}^{1} P_{y}\right)=1 / 4\left[\cos 6 \pi J \tau_{2}+3 \cos 2 \pi J \tau_{2}\right] \text { and } \\
& I\left(A l_{z}^{2} P_{y}\right)=1 / 4\left[\cos 6 \pi J \tau_{2}-\cos 2 \pi J \tau_{2}\right] \\
& I\left(A l_{z}^{1} P_{y}\right)=1 / 8\left[3+4 \cos 4 \pi J \tau_{2}+\cos 8 \pi J \tau_{2}\right] \text { and } \\
& I\left(A l_{z}^{2} P_{y}\right)=1 / 8\left[-1+\cos 8 \pi J \tau_{2}\right]
\end{aligned}
$$

If the ${ }^{31} \mathrm{P}$ spin is only coupled to ${ }^{27} \mathrm{Al}^{1}$ and ${ }^{27} \mathrm{Al}^{2}\left(\mathrm{n}^{\prime}=2\right)$, the transfer, 60 which is proportionnal to $-1+\cos \left(4 \pi J \tau_{2}\right)$, will be complete when 
$\tau_{2}=(4 \mathrm{~J})^{-1}$. Hence, the diagonal signal, which is proportional to $1+\cos \left(4 \pi J \tau_{2}\right)$, vanishes, and no diagonal will be observed in the $2 \mathrm{D}$ spectrum. The diagonal peak and the cross peak are of opposite signs, and this allows to discriminate the cross peak contribution ${ }_{65}$ from the residual diagonal signal. This is especially useful whenever the refocalization is not complete, as some residual diagonal signals will be observed.

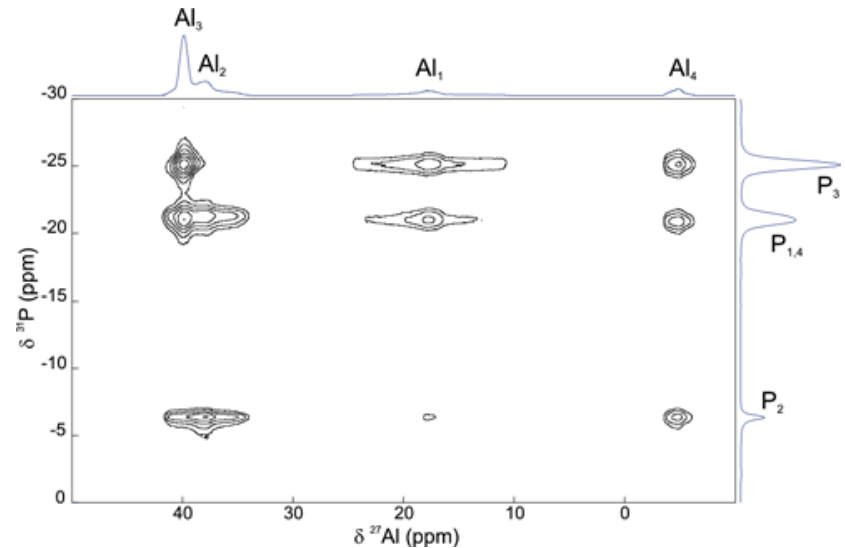

Fig. $2{ }^{27} \mathrm{Al}(\mathrm{CT})-{ }^{31} \mathrm{P}$ HMQC spectrum of an $\mathrm{AlPO}_{4}-14$ sample, performed at 17.6T ( ${ }^{1} \mathrm{H}$ Larmor frequency of $\left.750 \mathrm{MHz}\right)$, using MAS, in a $4 \mathrm{~mm}$ rotor $\left(v_{\mathrm{r}}=14 \mathrm{kHz}\right)$. The corresponding projections are shown on the spectrum, as well as the peak assignments. $\mathrm{Al}_{1}$ and $\mathrm{Al}_{4}$ feature large second order quadrupolar broadenings.

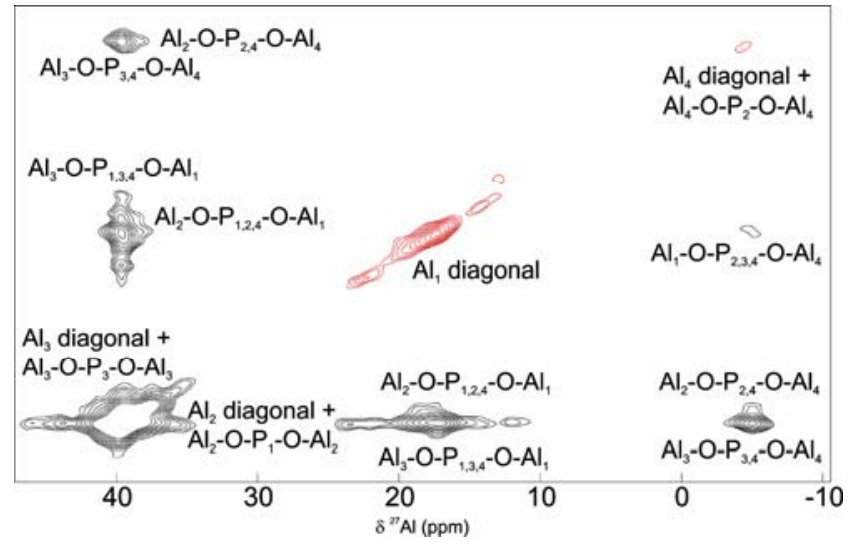

Fig.3 H-HSQC spectrum of an $\mathrm{AlPO}_{4}-14$ sample, featuring the $\mathrm{Al}-\mathrm{Al}$ pairs giving rise to negative cross-peaks (in black) and the positive diagonal signals (in red). The spectrum was obtained in the experimental conditions mentioned in the Figure 2 caption. The pulse sequence was run using the following parameters: the recycling delay $\mathrm{d}_{1}$ was set to $250 \mathrm{~ms}$, the $\tau$ period for the INEPT transfer was set to 40 rotor periods $\tau_{\mathrm{r}}$ (optimized for the best overall signal-to-noise ratio, as the different ${ }^{27} \mathrm{Al}-$ ${ }^{31} \mathrm{P}$ pairs feature distinct scalar couplings and dephasing times), the $\tau_{2}$ period was set to $120 \tau_{\mathrm{r}}$ (in order to maximize the negative cross peaks intensities), and a Z-filter of $300 \tau_{\mathrm{r}}$ was used. 16 dummy scans and 1152 scans were acquired for each of the $128 t_{1}$ increments and exponential broadening $(\mathrm{LB}=100 \mathrm{~Hz})$ was applied in both dimensions.

When $n '=3$ or 4 , the diagonal signal cannot be suppressed, but an optimum value for $\tau_{2}$ can be determined experimentally by 70 optimizing $\tau_{2}$ to get the maximum negative signal (which characterizes the cross peak). This optimum values are found to be $\tau_{2} \approx(5 \mathrm{~J})^{-1}$ and $(6 \mathrm{~J})^{-1}$ when $\mathrm{n}^{\prime}=3$ or 4 , respectively, provided all the scalar couplings are equal and relaxation or broadening phenomena can be neglected.

75 This new H-HSQC pulse sequence has been tested on a powder sample of $\mathrm{AlPO}_{4}-14 .^{9-11}$ The ${ }^{27} \mathrm{Al}$ and ${ }^{31} \mathrm{P}$ spectra of $\mathrm{AlPO}_{4}-14$ have been completely assigned ${ }^{9}$ and its crystal structure is well known. ${ }^{12}$ Each ${ }^{31} \mathrm{P}$ atom is connected to four ${ }^{27} \mathrm{Al}$ atoms via an oxygen atom and each ${ }^{27} \mathrm{Al}$ atom is connected to four ${ }^{31} \mathrm{P}$ atoms also via an 80 oxygen atom. Four different $\mathrm{Al}$ sites and four different $\mathrm{P}$ sites can be distinguished. These are numbered according to Ref. [9], from wich the expected connectivities are also extracted. The HMQC ${ }^{13}$ spectrum is shown as a reference in Figure 2 and the H-HSQC spectrum featuring the expected connectivities is shown in Figure ${ }_{85} 3$. In the H-HSQC spectrum, negative cross peaks are observed for every pair of ${ }^{27} \mathrm{Al}$ atoms as expected, except for $\mathrm{Al}_{1}$ which is never connected to another $\mathrm{Al}_{1}$ atom. Hence the signal appearing at $\left(\delta\left(\mathrm{Al}_{1}\right), \delta\left(\mathrm{Al}_{1}\right)\right)$ is always positive and purely diagonal, whereas the signal at $\left(\delta\left(\mathrm{Al}_{4}\right), \delta\left(\mathrm{Al}_{4}\right)\right)$, stemming from the diagonal signal and 90 from the $\mathrm{Al}_{4}-\mathrm{O}-\mathrm{P}_{2}-\mathrm{O}-\mathrm{Al}_{4}$ motives exhibits a negative sign for slightly longer delays $\left(130 \tau_{\mathrm{r}}\right)$ and is observed in $1 \mathrm{D}$ mode using a larger number of scans. Signals stemming from $\mathrm{Al}_{3}$ are actually stronger than the others, due to the fact that $\mathrm{Al}_{3}$ is less affected by second-order quadrupolar broadenings (as seen in the projections of

${ }_{95}$ Figure 2). The quadrupolar coupling constants and asymmetry parameters of $\mathrm{Al}_{1,2,3,4}$ are equal to $5.58,4.08,1.74$ and $2.57 \mathrm{MHz}$ and $0.97,0.82,0.63$ and 0.7 , respectively. ${ }^{10}$ Hence the cross peak $\left(\delta\left(\mathrm{Al}_{1}\right), \delta\left(\mathrm{Al}_{4}\right)\right)$ is not detectable, whereas the $\left(\delta\left(\mathrm{Al}_{4}\right), \delta\left(\mathrm{Al}_{1}\right)\right)$ cross peak is very weak.

100 We show that small scalar couplings $(\mathrm{J}=10-30 \mathrm{~Hz})$, persisting in solids under MAS conditions, can be used to generate an Homonuclear H-HSQC correlation experiment that characterizes the through bond connectivity of quadrupolar nuclei in solids across four chemical bonds. This experiment has been tested and 105 demonstrated on an $\mathrm{AlPO}_{4}-14$ sample where it allows for a detailed characterization of the Al-O-P-O-Al motives in a complex three dimensional bonded network. This experiment opens new possibilities for the characterization of complex chemical bond networks in perfectly crystalline, disordered or amorphous solids.

\section{${ }_{110}$ Notes and references}

$\dagger$ We acknowledge financial support from CNRS UPR4212, FR2950, MIAT and Région Centre and we are grateful to Pr. P.J. Grandinetti for stimulating discussions.

1 D. Iuga, C. Morais, Z. Gan, D.R. Neuville, L. Cormier and D. 115 Massiot, J. Am. Chem. Soc., 2005, 127, 11540-11541.

2 M. Eden, J. Grinshtein and L. Frydman, J. Am. Chem Soc., 2002, 124, 9708-9709.

3 M. Eden, H. Annersten and A. Zazzi, Chem. Phys. Lett., 2005, 410, 24-30.

1204 G.Mali, G.Fink and F.Taulelle, J. Chem. Phys., 2004, 120, 28352845.

5 G. Bodenhausen and D.J. Ruben, Chem. Phys. Lett., 1980, 69, 185189.

6 A.P.M. Kentgens and R. Verhagen, Chem. Phys. Lett., 1999, 300, 435.

7 H.-T. Kwak, S. Prasad, T. Clark and P.J. Grandinetti, Solid State NMR, 2003, 24, 71-77.

8 F. Fayon, C. Roiland, L. Emsley and D. Massiot, J. Magn. Reson., 2006, 179, 50-58.

1309 C.A. Fyfe, H. Meyer zu Altenschildesche, K.C. Wong-Moon, H. Grondey and J.M Chezeau, Solid State NMR, 1997, 9, 97-106.

10 C. Fernandez, J.-P. Amoureux, J.M. Chezeau, L. Delmotte and H. Kessler, Microporous Mater., 1996, 6, 331-340.

11 J.W. Wiench and M. Pruski, Solid State NMR, 2004, 26, 51-55.

13512 M. Helliwell, V. Kaucic, G.M.T. Cheetham, M.M. Harding, B.M. Kariuki, P.J. Rizkallah, Acta Crystallogr., 1993, B49, 413.

13 D. Massiot, F. Fayon, B. Alonso, J. Trebosc, J.P. Amoureux, J. Magn. Reson., 2003, 164, 160-164. 


\section{Supplementary Materials}

140

\section{1) Pulse sequence}

\#include $<$ Avance.incl $>$

\#include $<$ Delay.incl $>$

145

"p5=p1*2"

"p12=p11*2"

"d0=0u"

"d6=(16)*(1s/cnst31)-(p1)"

150 "d8=(18)*(1 s/cnst31)-(p1)"

"d7=(16-116)*(1s/cnst31)-(p1)"

"d3=(13)*(1s/cnst31)"

"d11=30m"

$1551 \mathrm{ze}$

d11 pl3:f3

$2 \mathrm{~d} 1$

; optional DFS enhancement

\#ifdef dfs

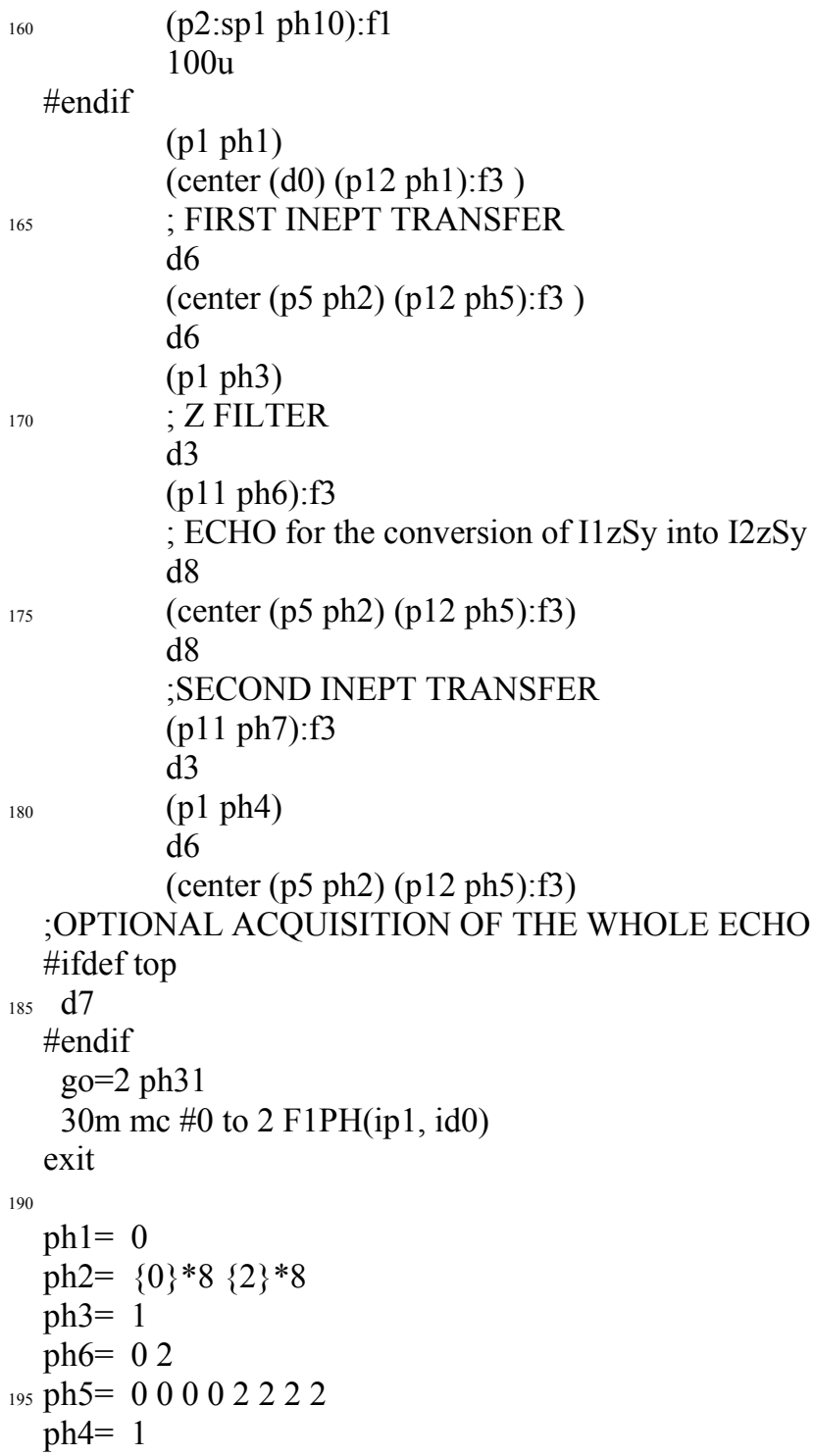

$\mathrm{ph} 7=\begin{array}{llll}0 & 0 & 2 & 2\end{array}$

ph31=0 0220

ph1 $1=1$

200 \#ifdef dfs

ph $10=0$

\#endif

;pl1 : f1 channel - power level for pulse (default)

$205 ;$ pl3 : f3 channel - power level for pulse (default)

;p1 : f1 channel - 90 degree high power pulse

;p5 : f1 channel - 180 degree high power pulse

;p2 : dfs

;p11 : f3 channel - 90 degree high power pulse

${ }_{210} ; \mathrm{p} 12$ : $\mathrm{f} 3$ channel - 180 degree high power pulse

;d0 : incremented delay (2D)

; 11 : relaxation delay; $1-5 * \mathrm{~T} 1$

[3 usec]

;d6 : INEPT transfer

; 7 : INEPT transfer

${ }_{215} ; \mathrm{d} 8$ : REFOCUSING DELAY

;nd0: 1

;FnMODE: States

\section{2) Notes}

220

Provided the $90^{\circ} / 180^{\circ}$ pulses for nuclei I and $\mathrm{S}$ have been calibrated, the $\mathrm{d} 6$ and $\mathrm{d} 8$ delays (corresponding to $\tau$ and $\tau_{2}$ ) can be optimized:

First, $d 8 / 18$ is set to a very small value (i.e. $3 \mu \mathrm{s}$ ), in order to ${ }_{225}$ prevent the $\mathrm{I}_{\mathrm{z}}^{1} \mathrm{~S}_{\mathrm{y}} \rightarrow \mathrm{I}_{\mathrm{z}}^{2} \mathrm{~S}_{\mathrm{y}}$ conversion. The INEPT delay d6 is optimized to generate the highest observable signal. Then $\mathrm{d} 8$ is optimized in order to maximize the $\mathrm{I}_{\mathrm{z}}^{1} \mathrm{~S}_{\mathrm{y}} \rightarrow$ $\mathrm{I}_{\mathrm{z}}^{2} \mathrm{~S}_{\mathrm{y}}$ transfer. 